\title{
Comparisons between some composites reinforced with corn leaves and different matrices
}

\author{
Alexandru Ioan Rădoi ${ }^{1}$, Cosmin Mihai Mirițoiu ${ }^{1, *}$, and Claudiu Nicolicescu ${ }^{1}$ \\ ${ }^{1}$ University of Craiova, Faculty of Mechanics, Calea Bucureşti Street, No. 107, Code 200512, \\ Craiova, Romania
}

\begin{abstract}
In this paper we build some composite materials reinforced with corn leaves. In order to build the samples, we have firstly created some strips in this way: we put the corn leaves, continuously, on a sheet of paper where we apply a this layer of resin (we have used epoxy and polyester ones). We have waited for the resin polymerization 48 hours, recommended by the producer. We have put the corn leaves layers in the director of the tensile test (because we will test the samples to tensile). We have made 10 strips and we have glued them together by using the same synthetic resins (epoxy and polyester). In the end we have obtained some composites reinforced with strips from corn leaves and paper sheet, and the matrix is made from epoxy and polyester resins. From the obtained plate, we have cut some samples in order to study their statically mechanical characteristics by tensile test. The samples were tested on an universal testing machine INSTRON 1000 HDX which is assisted by a software called Bluehill. The samples have a rectangular section We have determined: the elongation at break, the breaking strength and the Young modulus. We have also studied the samples breaking area. .
\end{abstract}

\section{Introduction}

\subsection{State of art regarding researches with corn}

In the process of composite materials manufacturing, the corn has been used as a reinforcement in many studies. For example, in [1] samples were made from composite materials with lignosulfonate matrix reinforced with cob powder from cobs. Several specimens were used, with different proportions of the reinforcement and the particle size. There were obtained values between 9-16 MPa for the breaking strength and 290..320 MPa for the Young modulus.

In [2] studies are made on composite materials with $30 \%$ lignosulfonate powder and $70 \%$ natural fibers such as flax, hemp, straw, jute. Bending stresses were determined and an

* Corresponding author: miritoiucosmin@yahoo.com 
modulus of elasticity of approximately 7700 and bending strength of $24.1 \mathrm{MPa}$ were determined.

Other studies are given in [3], [4], [5] and [6]. In [6] the mechanical properties of particulate composites from corn cobs combined with fiberglass and epoxy resin were investigated. The specimens were abbreviated with CGE1 (27.5\% corn, $2.5 \%$ fiberglass), CGE 2 (25\% corn, 5\% fiberglass), CGE 3 (22.5\% corn, 7.5\% fiberglass) and CGE 4 (20\% corn, $10 \%$ fiberglass). The tensile strength and tensile modulus are between $14 \ldots 18 \mathrm{MPa}$ and $600 . .900 \mathrm{MPa}$.

Research has been done on the integration of corn stalks in construction. Thus, in [7], research is given on the use of corn stalks for the insulation of buildings in combination with magnesium phosphate cement, the mixture meeting the conditions to be used in civil engineering.

In [8] the are manufactured biodegradable composite materials with the matrix obtained from corn starch and corn leaves as a filler substance. The corn starch was extracted from the corn cobs by using the method from [9]. There were obtained, for the final samples, the next values: breaking strength between $6 \ldots 12 \mathrm{MPa}$, Young modulus between 100 and 600 $\mathrm{MPa}$, elongation at break between 2,5 and 7\% for the samples built in the study from [8].

\section{The composite samples manufacturing}

In the fist phase of composite manufacturing, we have created some sheets made in this way: on a sheet of paper we have applied the matrix and under the matrix we have placed side by side the corn ear leaves (Fig. 1).

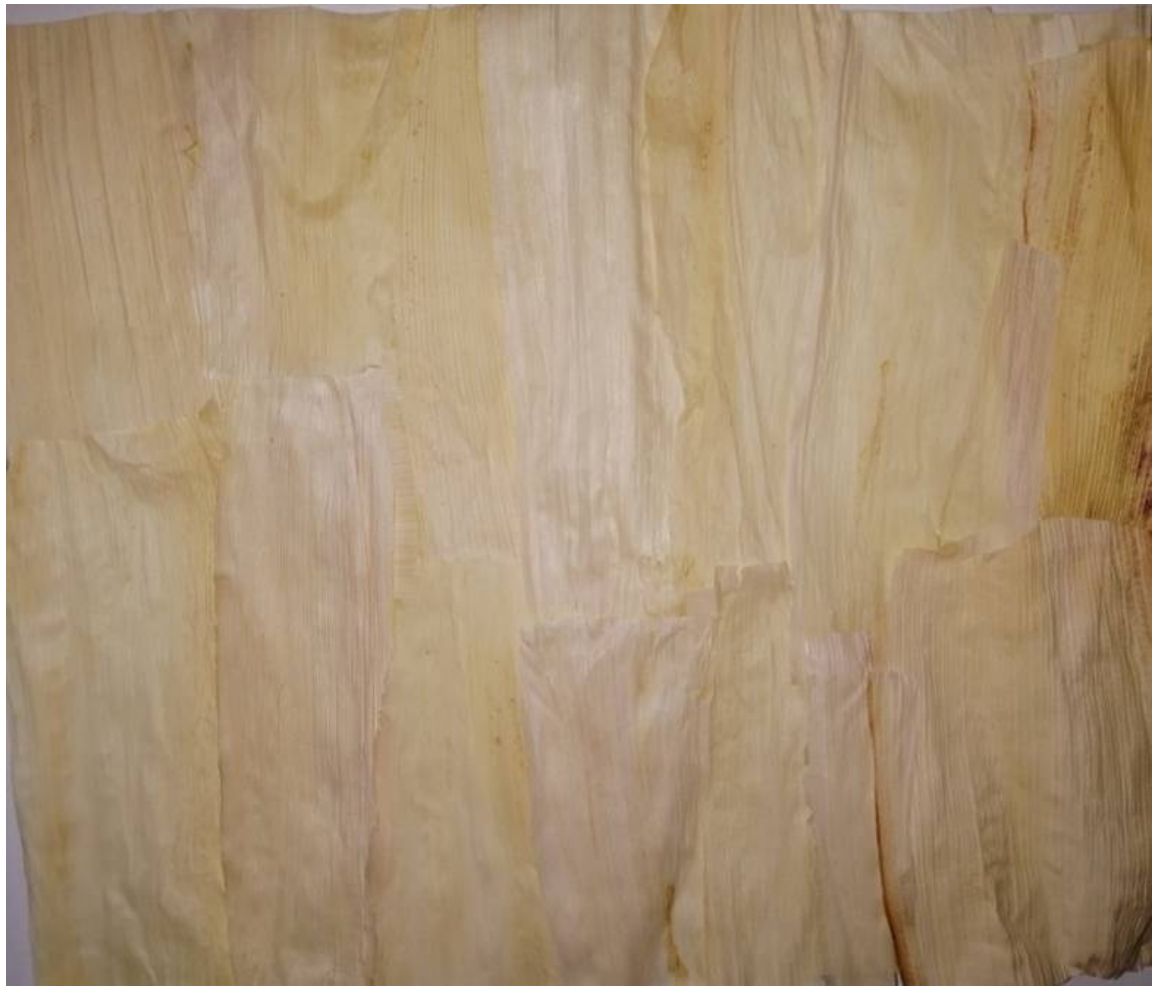

Fig. 1. A sheet from epoxy resin and corn ear leaves 
We have created ten sheets like the one presented in fig. 1 . Then, we glued the sheets by applying resin on them (epoxy for the first set, then polyester for the second set - Fig. 2). The resin was applied manually (Fig. 2). The final obtained plate is presented in Fig. 3. The final plate has A4 sheet dimensions. From this plate we cut samples with a width of $25 \mathrm{~mm}$, $8 \mathrm{~mm}$ thickness and the length $200 \mathrm{~mm}$ (Fig. 4).

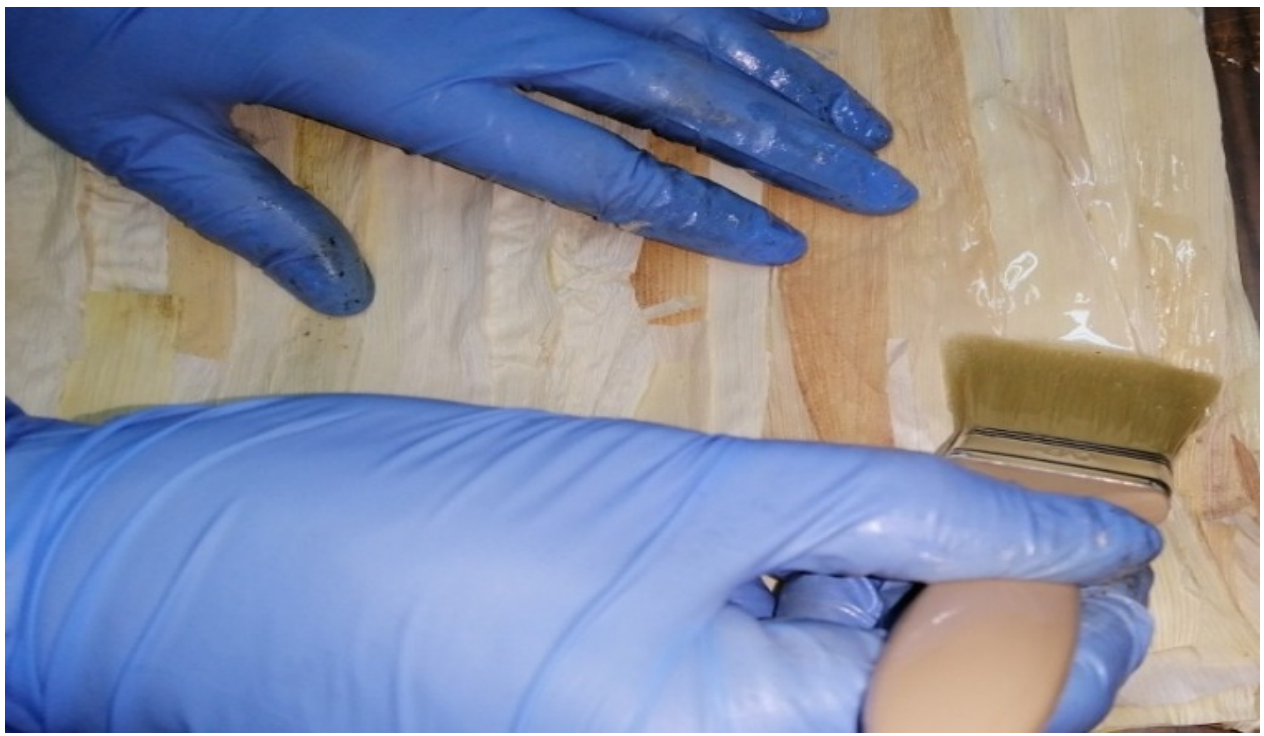

Fig. 2. Applying the epoxy resin on the created sheets (paper+corn ear leaves)

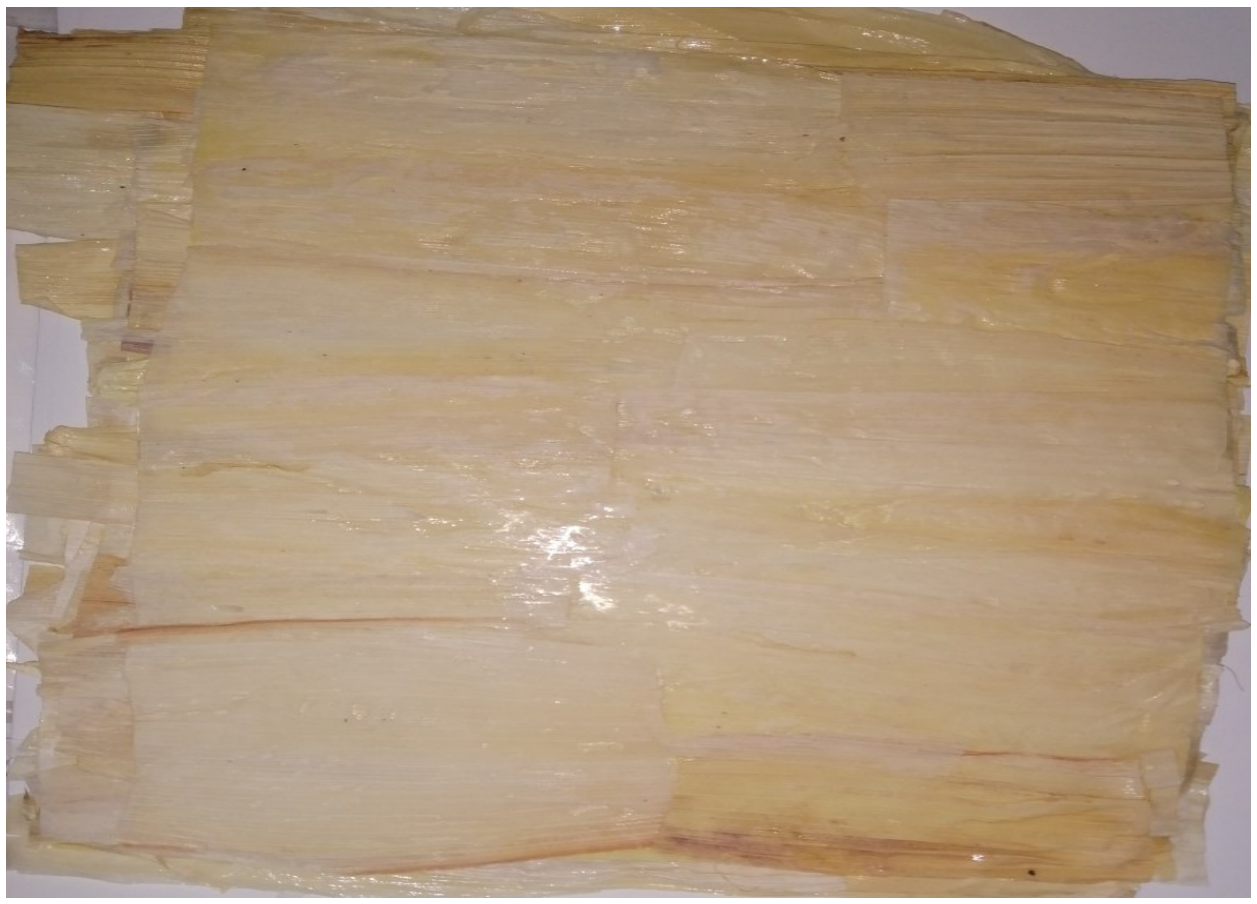

Fig. 3. The final created plate (paper+corn ear leaves) 


\section{Tensile Tests}

\subsection{Characteristics curves}

From the obtained plate, we have cut some samples in order to study their statically mechanical characteristics by tensile test. For each type, we have cut 5 samples to test them. The samples were tested on an universal testing machine INSTRON 1000 HDX which is assisted by a software called Bluehill. The samples have a rectangular section We have determined: the elongation at break, the breaking strength and the Young modulus. An example with the tested sample is presented in fig. 4. The stress-strain curves for two representative samples from epoxy+corn ear leaves/paper and from polyester resin + corn ear leaves/paper are presented in fig. 5 and 6.

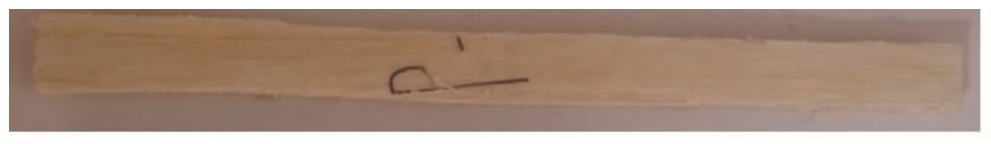

Fig. 4. A sample for the static mechanical characteristics tests (epoxy+corn ear leaves/paper)

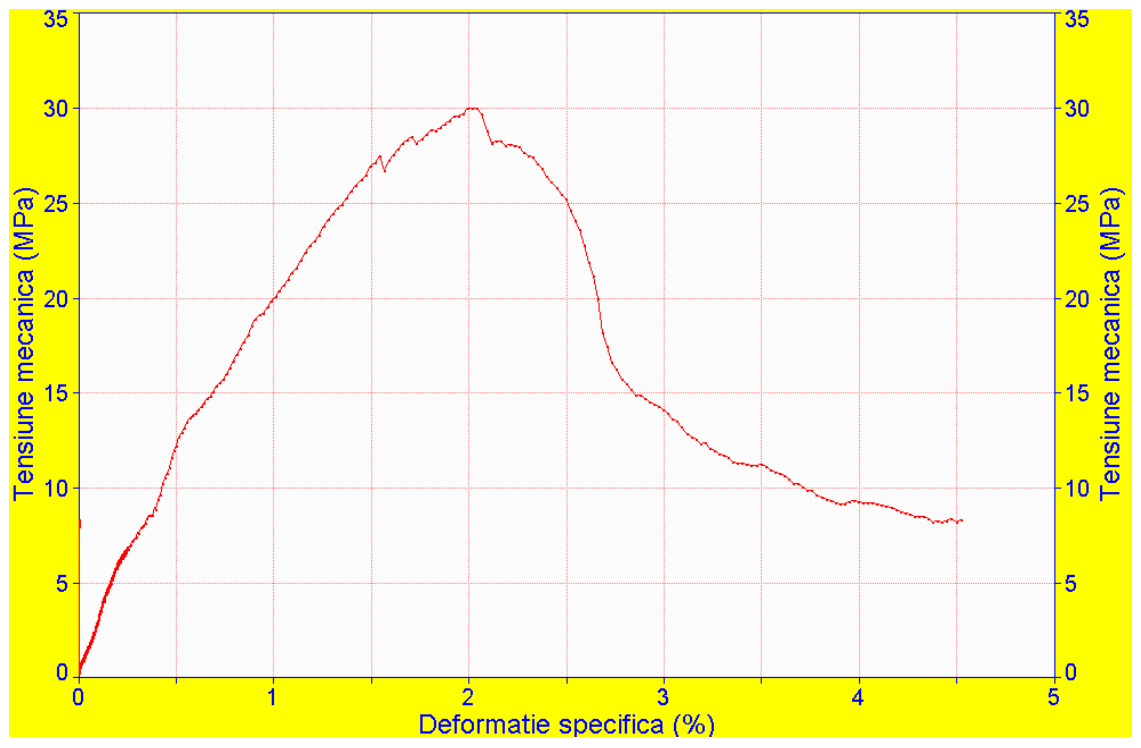

Fig. 5. The stress-strain curve (paper+corn ear leaves and epoxy matrix)

The mechanical characteristics determination for the two studied materials (with epoxy and polyester resins) are presented in Tables 1 and 2.

Table 1. Mechanical parameters for samples made of paper+corn ear leaves and epoxy matrix

\begin{tabular}{|c|c|c|c|}
\hline Characteristic & $\mathrm{E}(\mathrm{MPa})$ & $\sigma_{\mathrm{r}}, \mathrm{R}_{\mathrm{m}}(\mathrm{MPa})$ & $\mathrm{A}(\%)$ \\
\hline Value & $2470 \pm 210$ & $30 \pm 7$ & $2 \pm 1.5$ \\
\hline
\end{tabular}

Table 2. Mechanical parameters for samples made of paper+corn ear leaves and polyester matrix

\begin{tabular}{|c|c|c|c|}
\hline Characteristic & $\mathrm{E}(\mathrm{MPa})$ & $\sigma_{\mathrm{r}}, \mathrm{R}_{\mathrm{m}}(\mathrm{MPa})$ & $\mathrm{A}(\%)$ \\
\hline Value & $2200 \pm 175$ & $24 \pm 4$ & $5 \pm 2$ \\
\hline
\end{tabular}


In Tables 1 and 2 we have marked with $E$ the elasticity modulus, $\sigma_{\mathrm{r}}, \mathrm{R}_{\mathrm{m}}$ the breaking strength and with A the elongation at break.

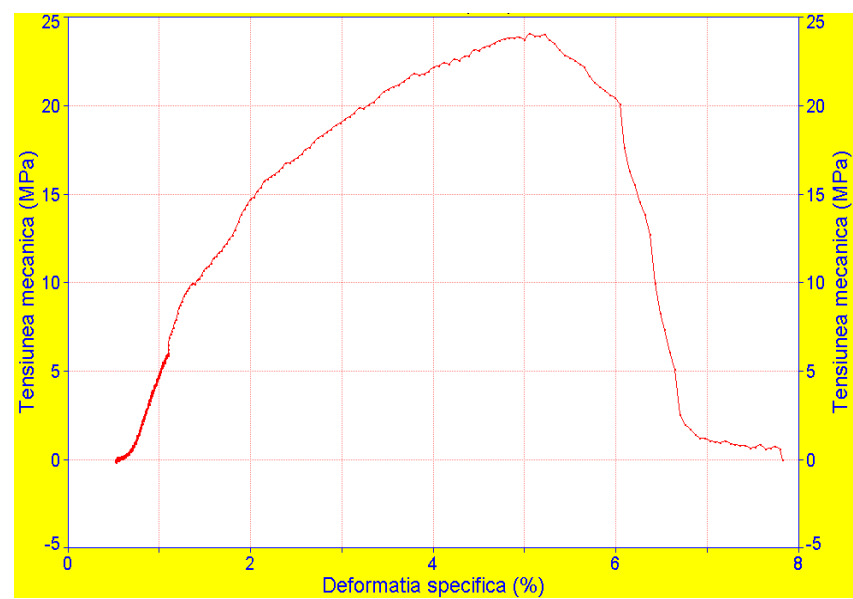

Fig. 6. The stress-strain curve (paper+corn ear leaves and polyester matrix)

\subsection{Analytical validation and macroscopic study for the breaking area}

We propose the usage of the relationships (1) and (2) for the elasticity modulus and breaking strength calculus.

$$
\begin{gathered}
E=E_{m} V_{m}+E_{f} V_{f} \cdot k \cdot k_{1} \\
\sigma_{r}=\sigma_{f} V_{f} \cdot k \cdot k_{1}
\end{gathered}
$$

In (1) and (2) we have marked with: $E_{m}, E_{f}$ the matrix and fibers modulus of elasticity, $\mathrm{V}_{\mathrm{m}}, \mathrm{V}_{\mathrm{f}}$ the volume fraction of matrix, $\mathrm{k}$ is a factor non-uniformity coefficient equal to 0.8 and takes into account that after the molding the corn ear leaves slightly moved from the initial position (we tried to put perfectly the reinforcement parallel to the tensile force) and $\mathrm{k}_{1}$ is an adhesion factor which characterizes the adhesion between the matrix and the reinforcement layers which is 0.65 (we observed defects in the samples after cutting them from the molded plate - Fig. 7). The factor $\mathrm{k}$ was determined by using the theory and considerations from [10]. The factor $\mathrm{k}_{1}$ was determined by analyzing the edge surface of the samples at stereomicroscope INSIZE type. There were determined summed values for the holes areas. Then, the $\mathrm{k}_{1}$ factor was appreciated as a difference from the total area minus the areas with holes. We tensile tested some corn ear leaves and we obtained the stress strain curve for a representative sample in Fig. 8 and the experimental results from Table 3.

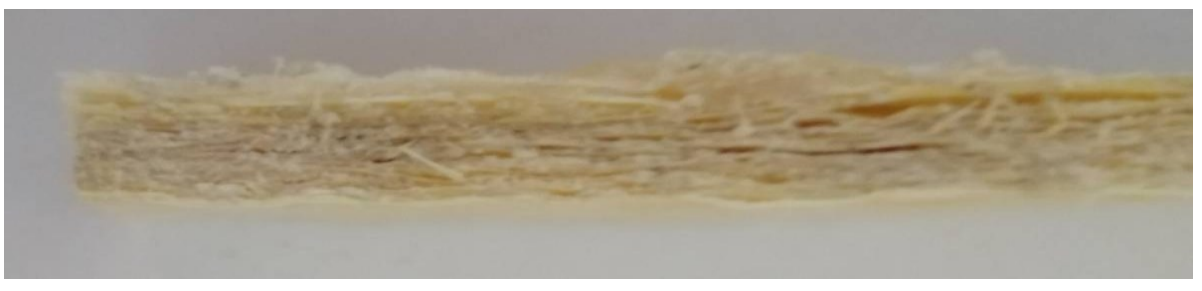

Fig. 7. Deffects in samples after cutting them from the plate 
Table 3. Mechanical parameters for samples made of ear leaves

\begin{tabular}{|c|c|c|c|}
\hline Characteristic & $\mathbf{E}(\mathbf{M P a})$ & $\boldsymbol{\sigma}_{\mathbf{r}}, \mathbf{R}_{\mathbf{m}} \mathbf{( M P a )}$ & $\mathbf{A ~ ( \% )}$ \\
\hline Value & $236 \pm 67$ & $5.3 \pm 3$ & $5.5 \pm 2.7$ \\
\hline
\end{tabular}

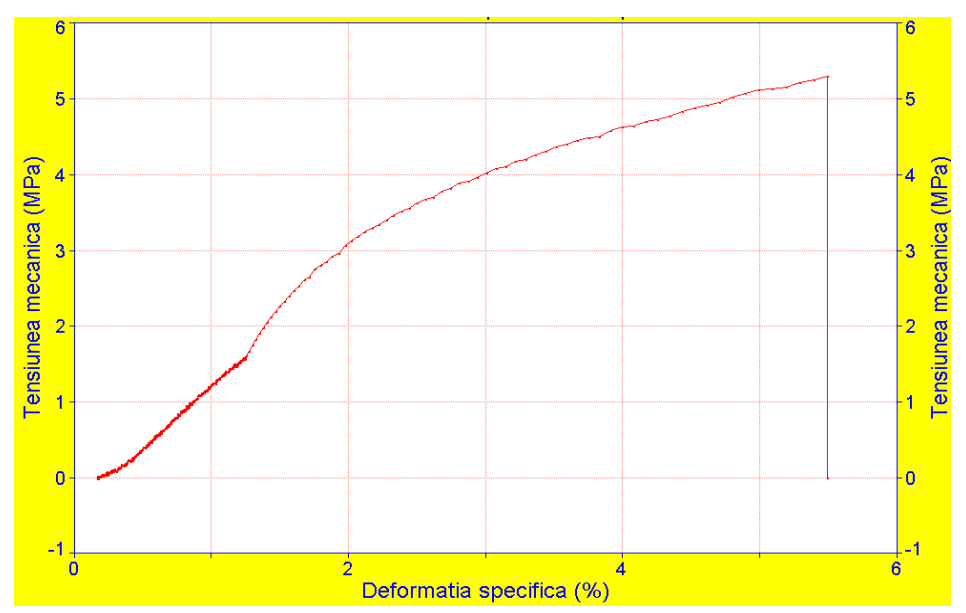

Fig. 8. Stress-strain curve for a corn ear leaf sample

If the formula (1) is used, we have obtained the values (3) for the epoxy resin and (4) for the polyester resin. If the formula (2) is used, we have obtained the values (5) for both resins (it will be considered that the whole stress is taken over by the paper, for both cases, because it has the highest breaking strength). We have also considered that the final breakage appears with the paper layer breakage.

$$
\begin{aligned}
& E=4027 \mathrm{MPa} \\
& E=2164 \mathrm{MPa} \\
& \sigma_{\mathrm{r}}=27.547 \mathrm{MPa}
\end{aligned}
$$

Between the modulus of elasticity values, we obtained the following errors: $19.01 \%$ (epoxy) and $1.06 \%$ (polyester). Between the breaking strength values, we obtained the following errors: $8.9 \%$ (epoxy) and $12.87 \%$ (polyester).

A similar calculus formula is given in [11] for the modulus of elasticity and breaking strength. From the produce datasheet, the modulus of elasticity of the epoxy resin is 3530 $\mathrm{MPa}$, and the breaking strength is $99.1 \mathrm{MPa}$ [12]. For the polyester resin, the modulus of elasticity is $600 \ldots 1400 \mathrm{MPa}$ and the breaking strength is $61 . .65 \mathrm{MPa}$ [13].

We have studied by using a digital stereomicroscope INSIZE the breaking areas for the tested samples. Some images are presented in Fig. 9. We can conclude that the resin had a brittle fracture. Both the corn ear leaves and the paper had a ductile fracture. There also appeared some snatches in the reinforcement layers because of low adhesion obtained between the reinforcement sheets and the matrix used (epoxy and polyester). 

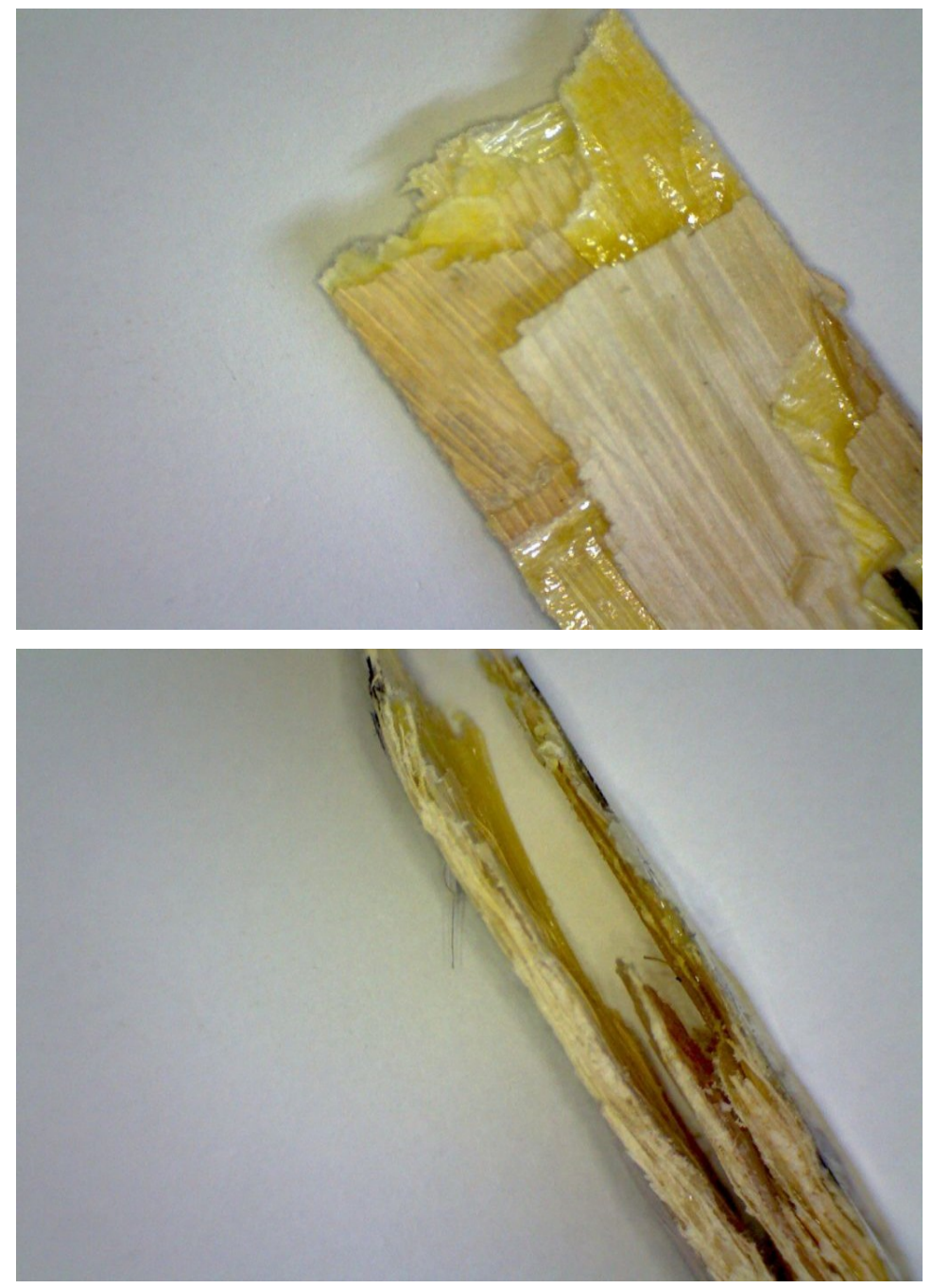

Fig. 9. Samples breaking area

\section{Conclusions}

In this paper some new original composites are moulded and manufactured at the room temperature. There are used two different matrices: polyester and epoxy ones. The reinforcement is compound of sheets of paper and on those sheets of paper there are placed, side by side, corn ear leaves. Then a plate is obtained in the end and some samples are cut from this plate, with the next dimensions: $200 \mathrm{~mm}$ free length, $8 \mathrm{~mm}$ thickness and $25 \mathrm{~mm}$ width. For those new created materials, the static mechanical characteristics are determined, and the analytical validation is made.

From the Fig. 5 and 6 we can see that the characteristic curves have three different domains: in the first domain, the loading is supported by both matrix and fibers, which assures the composite material cohesion and also the Hook law is checked, appearing a proportionality between stress and strains; in the second domain there appears a nonlinearity in the characteristic curve because the tensile strength in the matrix is reached and it breaks in some points; in this domain the adhesion between the fibers and the matrix is 
lost and pluckings of reinforcement from the matrix appear; in the last domain there is almost a linearity between the stress and strain which suggests that the composite breakage is made when in the fibers is reached the tensile strength; the are some inflexion points until the samples breakage which show that not all the fibers were broken at the same time, a part of them broke in the same time and the loading is subjected by the remained fibers.

From the Fig. 8 we can see that the corn ear leaves have an almost linear stress-strain curve until the breakage. From the Fig. 9 we can see that there appeared snatches in the reinforcement layers because of low adhesion obtained between the reinforcement sheets and the matrix used (epoxy and polyester).

This type of composites can be used for: planes floor building, door frames, roofing sheets, ships floor building, walls of civil constructions, concrete forming or to strengthen thin reinforced concrete slabs.

\section{References}

1. Tribot, A., et. al., Industrial Crops \& Products, 123, (2018)

2. Privas, E., Navard, P., Carbohydr. Polym, 93, (2013)

3. Luo, Z., Li, P., Cai, D., Chen, Q., Qin, P., Tan, T., Cao, H., Ind.Crops Prod., 95 , (2017)

4. Panthapulakkal, S., Sain, M., Composites: Part A, 38, (2007)

5. Luo, H., Xiong, G., Ma, C., Chang, P., Yao, F., Zhu, Y., Zhang, C., Wan, Y., Polymer Testing, 39, (2014)

6. Garadimani, K.R., Raju, G.U., Kodancha, K.G., Am. J. Mater. Sci. 5, 3C, (2015)

7. Ahmad, M.R., Chen, B., Oderji, S.Y., Mohsan, M., Energy and Buldings, 173, (2018)

8. Crutis, P. T., Bader, M. G. , Bailey, J. E., Journal of Material Science, 13, (1978)

9. Ibrahim, M.I.J., Sapuan, S.M., Zainudin, E.S., Zuhri, M.Y.M, International Journal of Biological Macromolecules, 139, (2019)

10. Ciucă, I., Bolcu, D., Stănescu, M.M., Universitaria Publishing, Craiova, (2010)

11. Ali, A., Wani, T.A., Masoodi, F.A., J. Saudi Soc. Agric. Sci., 15, (2016)

12. https://www.resoltech.com/en/markets/1050-detail.html [Accessed 03.02.2021]

13. Davallo, M., Pasdar, H., Mohseni, M., International Journal of ChemTech Research, 2, (2010) 